\title{
Cloud-based IoT Platform DC-DC Power Converter (Non-Ideal)
}

\author{
Meshari J. Al Jandal, Khaled S. Al Rasheed, Muhammad R. Jamal
}

\begin{abstract}
This paper describes a modularized smart system architecture which is integrated with Internet of Thing (IoT) into the DC-DC converters to build a programmable technique to leverage machine learning algorithms to predict possible future faults to the system. In addition, it facilitates the performance optimization of the boost converter. This system can be established with low computing hardware to simulates the control behavior and data-driven method of IoT-based, due to the unreliability initiated from the integration of IoT technology and power electronic converters. In response to these challenges, the current paper addresses a scientific approach using small signal analysis of dc-dc boost converter (non-Ideal) with closed loop control to analyze the small deviations or abnormalities in transient region and the steady-state operating point. Complete state-space analysis is done to obtain output voltage using pulse width modulation techniques for boosting the voltage of the input voltage to a higher level by momentarily storing and release the energy in the conductor. The model of the converter is designed and simulated using voltage mode controlling method. Digital implementation based on Arduino platform was implemented to compensate perturbations of sudden load variation either on voltage or current loads. A Simulation study is conducted to validate the result of the step-up dc-dc converter using MATLAB.
\end{abstract}

Keywords; - boost converter; continuous/discontinuous condition mode; voltage-mode control; pulse width modulation; close-loop control; Internet of things IOT; linearized; parasitic

\section{INTRODUCTION}

In the history of technological developments in the field of power electronics, DC power supply technology has been thought of as an essential part of electronic circuits [2]. It is one of the most widely used categories of electronic circuits and has been extensively used to control the output voltage to an average value with maximum current capability. In various applications, DC power supplies are used in personal computers, telephones, medical equipment, and aerospace military equipment $[1,4,5]$. Perturbations present in the raw DC voltage output during operation occur due to abrupt changes in the input voltage of the DC power supply, which usually arise due to conversion of the AC supply converted to DC by using electrical elements such as transformers, filters, and rectifiers.

Manuscript received on October 07, 2021.

Revised Manuscript received on October 10, 2021.

Manuscript published on November 30, 2021.

* Correspondence Author

Eng. Meshari J. AlJandal, Power electrical department faculty Paaet. Kuwait

Dr. Khaled S. AIRasheed, Power electrical department faculty Paaet., Kuwait

Eng. Muhammad R. Jamal, Power electrical department faculty, Paaet, Kuwait

(C) The Authors. Published by Blue Eyes Intelligence Engineering and Sciences Publication (BEIESP). This is an open access article under the CC BY-NC-ND license (http://creativecommons.org/licenses/by-nc-nd/4.0/)
Hence, these explicit requirements have led researchers and developers to extend this area of research to maximize availability, mobility, and efficiency. The DC power supply is classified as a voltage regulator which maintains the output voltage within a limited range of $1 \%$ to $2 \%$ of the desired value irrespective of change in load, input voltage, output current, and temperature [1,2]. The two types of power supply are the linear voltage regulator and switching mode power supply (SMPS). Semiconductors devices such as transistors in the linear voltage regulator are different from in switching mode power supply in a number of respects in terms of operation. It operates in the active region mode despite voltage drops and heat dissipation which affect overall efficiency [6]. These regulators are relatively large in terms of size, but they are commonly used in signal processing and audio applications due to their capability of providing immunity to noise. In switching mode, the transistors operate in the saturation region to function as ON-OFF switches so that less power is dissipated during operation in contrast to the saturation mode $[4,7]$. Therefore, the voltage drop is very low when the current is high, consuming smaller amounts of energy and eventually high efficiency can be achieved. However, the losses increase during switching at high frequency leading to reduced efficiency [2]. Many topologies of power supply technology have been proposed to perform power conversion based on different techniques and circuit configurations. Figure 1 illustrates the categories of regulated power supply technologies:

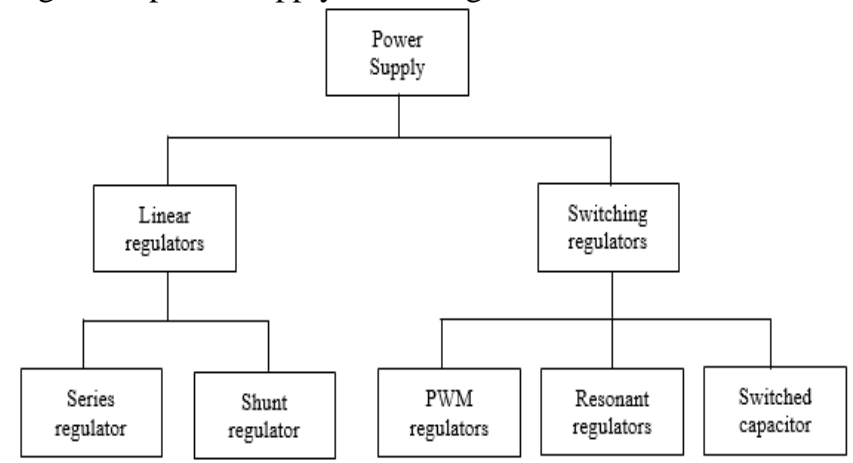

Figure 1: Categories of power supplies technology [2]

\section{PROBLEM STATEMENT}

The main focus of this paper is presented mainly in design a real prototype by developing a high quality printed circuit board PCB based on the fundamental circuit of the boost PWM DC-DC converter in order to verify the model in the state-space method $[2,21]$.

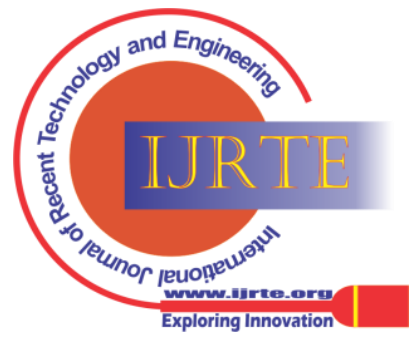




\section{Cloud-based IoT Platform DC-DC Power Converter (Non-Ideal)}

Experimentation is used to verify the accuracy of the state-space model by considering all possible sources of uncertainty and parasitics. The proposed controller is a proportional-integral (PI) system which is implemented digitally using the advance controller from the Arduino microcontroller family called the MKR1000 based on SAMD21 Cortex-M0 32-bit. The main contributions of this thesis are as follows:

a. The converter topology is a PWM step-up converter, operating at the boundary between the continuous current mode (CCM), and the discontinuous current mode (DCM).

b. The fundamental topology of the boost converter is simulated virtually to verify the functionality of the elements and validity of the chosen values of all components.

c. The switching frequency of the converter is valid when fs $\gg\left|\lambda_{\max }\right|$, where $\lambda \max$ represents the eigenvalue of $\mathrm{A}$, and $\mathrm{A}$ represents the state-space matrix of the statespace model $(\dot{x}=A x+B u)$, which means that the statespace average model is a good approximation at $\omega_{\max }<$ $\frac{2 \pi f_{S}}{10}$ (under one-tenth of the converter switching frequency) [1].

d. The experimental results are presented based on the resistance as the load, and the switching frequency is varied from $20 \mathrm{kHz}$ to $80 \mathrm{kHz}$.

e. Both simulation and experimentation are used in verifying the accuracy of the transfer function of the model.

f. The feedback signal represents the output voltage with a range of 0 to $3.3 \mathrm{~V}$ using a voltage divider. Therefore, the control method is called voltage-mode control.

g. The analysis confirms that the ratio of the load current Io to input DC current II is a function of the duty cycle.

h. The analysis showed that the gain voltage-dependent to duty cycle on CCM, whereas in DCM it depends upon other design parameters such as inductor size, switching frequency, and load current Io.

i. A new contribution to the application of the internet of things (IOT) has been made as part of a new area of research to develop smart converters able to optimize performance using machine learning and artificial intelligence in order to improve all possible of the technological lifestyle standard as shown Figure 2.

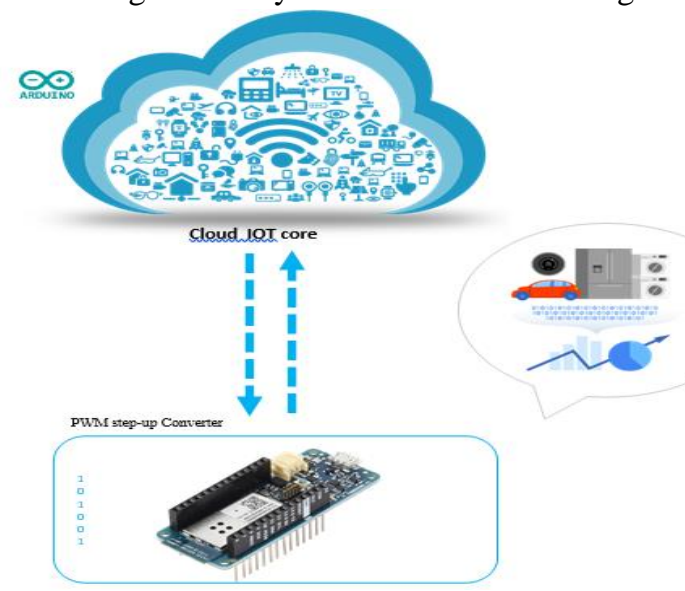

Figure 2: Internet of things application development for improving performance converter can be written as:
As discussed above, the analysis in this section is conducted so that an accurate average estimation can be achieved, where the parasitics must be included, and the state-space equation can be determined as follows:

Mod1: time interval: $0<\mathrm{t} \leq \mathrm{DT}$

Figure 4 , and the diode $\mathrm{D}=$ open. The dynamics of the

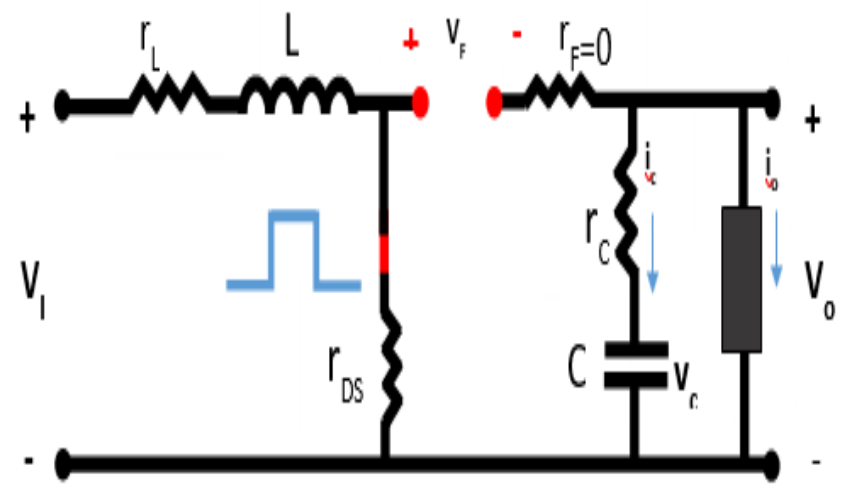

Figure 4: Equivalent circuit, switch $\mathrm{S}=\mathrm{ON}$ and diode is $\mathrm{OFF}$ Mod2: time interval: $\mathrm{DT}<\mathrm{t} \leq \mathrm{T}$

when the switch is zero $\mathrm{S}=$ open and the diode $\mathrm{D}=$ closed as follows;

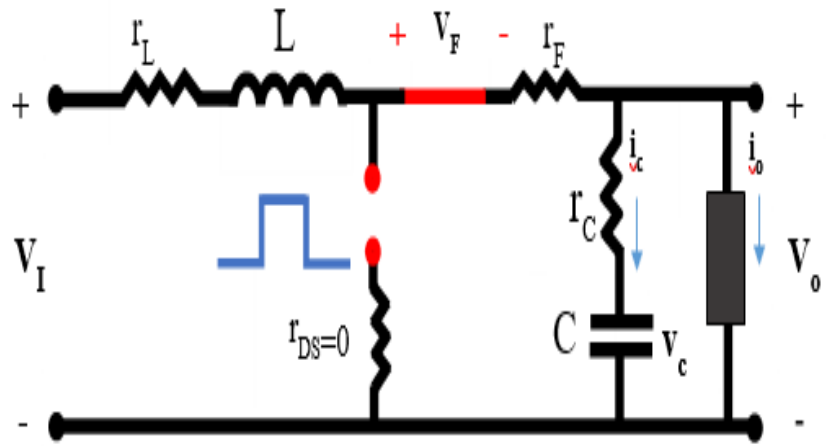

Figure 5: Equivalent circuit, switch $\mathrm{S}=\mathrm{OFF}$ and diode is ON

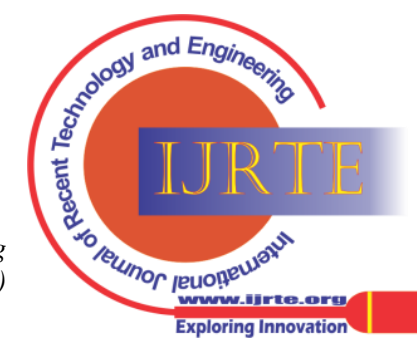


The switched state-space model's dynamics matrices of this switching converter can be obtained:

$$
\begin{aligned}
& A_{1}=\left[\begin{array}{cc}
\frac{-\left(r_{L}+r_{D S}\right)}{L} & 0 \\
0 & -\frac{1}{C\left(R_{o}+r_{c}\right)}
\end{array}\right]
\end{aligned}
$$

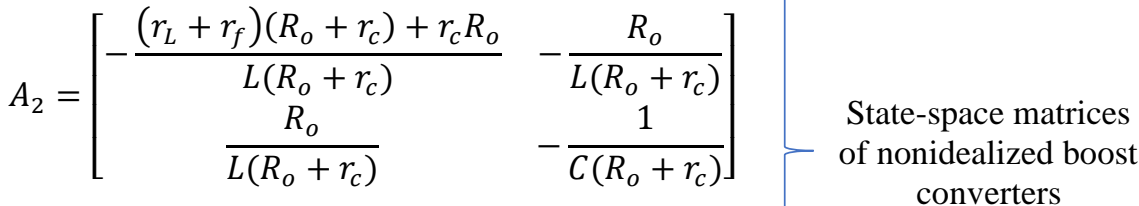

$$
\begin{aligned}
& B_{1}=\left[\begin{array}{ll}
\frac{1}{L} & 0 \\
0 & 0
\end{array}\right], B_{2}=\left[\begin{array}{cc}
\frac{1}{L} & -\frac{1}{L} \\
0 & 0
\end{array}\right] \\
& C_{1}=\left[\begin{array}{ll}
0 & \frac{R_{o}}{R_{o}+r_{c}}
\end{array}\right], C_{2}=\left[\begin{array}{ll}
\frac{r_{c} R_{o}}{R_{o}+r_{c}} & \frac{R_{o}}{R_{o}+r_{c}}
\end{array}\right] \\
& D_{1}=D_{2}=\left[\begin{array}{ll}
0 & 0
\end{array}\right]
\end{aligned}
$$

DC steady-state transfer functions (nonideal):

As mentioned above, $\frac{d x}{d t}$ goes to zero, $\dot{x}=A x+B u=0$ and $y=C x+D u$. Hence, the steady-state input VI to output Vo can be obtained as follows:

$$
\begin{gathered}
\dot{x}=A x+B u=0 \text { and } y=C x+D u \\
y=-C A^{-1} B u \\
V_{o}=-C A^{-1} B\left[\begin{array}{l}
V_{I} \\
V_{f}
\end{array}\right]
\end{gathered}
$$

let $d=D \quad(\hat{d}=0$ in $d c$ steady state $)$

$$
\begin{aligned}
& V_{o}=-\frac{1}{\left|A_{s . s}\right|}\left[\frac{r_{c} R_{o}}{R_{o}+r_{c}}(1-D) \frac{R_{o}}{R_{o}+r_{c}}\right] \\
& {\left[\begin{array}{cc}
-\frac{\left(r_{L}+r_{D S}\right)}{L} D-\frac{\left(r_{L}+r_{f}\right)\left(R_{o}+r_{c}\right)+r_{c} R_{o}}{L\left(R_{o}+r_{c}\right)}(1-D) & -\frac{R_{o}(1-D)}{L\left(R_{o}+r_{c}\right)} \\
\frac{R_{o}(1-D)}{C\left(R_{o}+r_{c}\right)} & -\frac{1}{C\left(R_{o}+r_{c}\right)}
\end{array}\right]^{-1}\left[\begin{array}{cc}
\frac{1}{L} & -\frac{1}{L}(1-D) \\
0 & 0
\end{array}\right]\left[\begin{array}{l}
\bar{v}_{I} \\
\bar{v}_{f}
\end{array}\right]}
\end{aligned}
$$

The determinant of the matrix $A_{s}$, can be found as:

$$
\begin{gathered}
\left|A_{s . s}\right|=\left[\frac{\left(r_{L}+r_{D S}\right)}{L C\left(R_{o}+r_{c}\right)}-\frac{\left(r_{L}+r_{F}\right)}{L C\left(R_{o}+r_{c}\right)}+\frac{r_{c} R_{o}}{L C\left(R_{o}+r_{c}\right)^{2}}\right] D+\frac{\left(r_{L}+r_{f}\right)}{L C\left(R_{o}+r_{c}\right)}+\frac{r_{c} R_{o}}{L C\left(R_{o}+r_{c}\right)^{2}}+\frac{R_{o}^{2}(1-D)^{2}}{L C\left(R_{o}+r_{c}\right)^{2}} \\
=-\frac{1}{\left|A_{s . S}\right|}\left[\frac{r_{c} R_{o}}{R_{o}+r_{c}}(1-D) \frac{R_{o}}{R_{o}+r_{c}}\right]
\end{gathered}
$$$$
\left[\begin{array}{cc}
-\frac{1}{C\left(R_{o}+r_{c}\right)} & \frac{R_{o}(1-D)}{L\left(R_{o}+r_{c}\right)} \\
-\frac{R_{o}(1-D)}{C\left(R_{o}+r_{c}\right)} & -\frac{\left(r_{L}+r_{D S}\right)}{L} D-\frac{\left(r_{L}+r_{f}\right)\left(R_{o}+r_{c}\right)+r_{c} R_{o}}{L\left(R_{o}+r_{c}\right)}(1-D)
\end{array}\right]\left[\begin{array}{cc}
\frac{1}{L} & -\frac{1}{L}(1-D) \\
0 & 0
\end{array}\right]\left[\begin{array}{l}
V_{I} \\
V_{f}
\end{array}\right]
$$

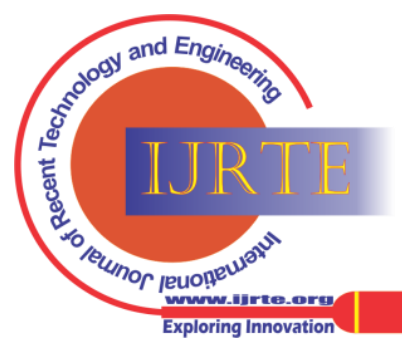




\section{Cloud-based IoT Platform DC-DC Power Converter (Non-Ideal)}

Now, to find the input VI to output $\mathrm{Vo}$, let $\mathrm{Vf}=0$, and the result can be obtained as follows:

$$
\begin{gathered}
=-\frac{1}{\left|A_{s . s}\right|}\left[\frac{r_{c} R_{o}}{R_{o}+r_{c}}(1-D) \quad \frac{R_{o}}{R_{o}+r_{c}}\right]\left[\begin{array}{r}
-\frac{1}{C\left(R_{o}+r_{c}\right)} \\
-\frac{R_{o}(1-D)}{C\left(R_{o}+r_{c}\right)}
\end{array}\right]\left[\begin{array}{c}
V_{I} \\
0
\end{array}\right] \\
\frac{V_{o}}{V_{I}}=\frac{R_{o}(1-D)\left(r_{c}+R_{o}\right)}{L C\left|A_{s . s}\right|\left(R_{o}+r_{c}\right)^{2}}=\frac{R_{o}(1-D)}{L C\left|A_{s . s}\right|\left(R_{o}+r_{c}\right)}
\end{gathered}
$$

This relationship is known as the steady-state transfer function of the boost converter. As shown in equation, the imposed reactance parasitics are not suited transient dynamics appear in the form of overshoot and steady-state error [1,21]. The duty cycle D for a given nominal input value can also be calculated off-line. The open-loop control for a constant output voltage Vo is conceivable for a stable value of the line input voltage, and the current load does not lead to any significant variation. State-space average small-signal model (non-ideal): For the small-signal $\hat{d}$ to output $\hat{v}_{o}$, the transfer function can be found taking into account that the line perturbations are zero:

$$
\begin{aligned}
& {\left[\begin{array}{l}
I_{L}+\hat{\imath}_{L} \\
V_{c}+\hat{v}_{c}
\end{array}\right]=\left[\begin{array}{cc}
{\left[-\frac{\left(r_{L}+r_{D S}\right)}{L}(D+\hat{d})-\frac{\left(r_{L}+r_{f}\right)\left(R_{o}+r_{c}\right)+r_{c} R_{o}}{L\left(R_{o}+r_{c}\right)}(1-D-\hat{d})\right]} & {\left[-\frac{R_{o}(1-D-\hat{d})}{L\left(R_{o}+r_{c}\right)}\right]} \\
{\left[\frac{R_{o}(1-D-\hat{d})}{C\left(R_{o}+r_{c}\right)}\right]} & {\left[-\frac{1}{C\left(R_{o}+r_{c}\right)}\right]}
\end{array}\right]\left[\begin{array}{l}
I_{L}+\hat{\imath}_{L} \\
V_{c}+\hat{v}_{c}
\end{array}\right]} \\
& +\left[\begin{array}{cc}
\frac{1}{L} & -\frac{1}{L}(1-D-\hat{d}) \\
0 & 0
\end{array}\right]\left[\begin{array}{l}
V_{I}+\hat{v}_{I} \\
V_{f}+\hat{v}_{f}
\end{array}\right] \\
& V_{o}+\hat{v}_{o}=\left[\begin{array}{ll}
\frac{r_{c} R_{o}}{R_{o}+r_{c}}(1-D-\hat{d}) & \frac{R_{o}}{R_{o}+r_{c}}
\end{array}\right]\left[\begin{array}{l}
I_{L}+\hat{\imath}_{L} \\
V_{c}+\hat{v}_{c}
\end{array}\right]
\end{aligned}
$$

At the steady-state the $\dot{X}=0$, and for simplicity the following is assumed:

$$
\begin{aligned}
& R_{m}=\frac{\left(r_{L}+r_{f}\right)\left(R_{o}+r_{c}\right)+r_{c} R_{o}}{\left(R_{o}+r_{c}\right)} \\
& R_{p}=r_{L}+r_{D S} \\
& R_{t}=\frac{R_{o}}{\left(R_{o}+r_{c}\right)} \\
& \text { Assumption to simplify } \\
& \text { the matrices } \\
& {\left[\begin{array}{c}
\hat{\imath}_{L} \\
\dot{\hat{v}}_{c}
\end{array}\right]=\left[\begin{array}{cc}
{\left[\left(-\frac{R_{p}}{L}+\frac{R_{m}}{L}\right) D-\frac{R_{m}}{L}+\left(\frac{R_{m}}{L}-\frac{R_{p}}{L}\right) \hat{d}\right]} & {\left[\frac{R_{t}}{L} D-\frac{R_{t}}{L}+\frac{R_{t}}{L} \hat{d}\right]} \\
{\left[-\frac{R_{t}}{C} D+\frac{R_{t}}{C}-\frac{R_{t}}{C} \hat{d}\right]} & {\left[-\frac{R_{t}}{C R_{o}}\right]}
\end{array}\right]\left[\begin{array}{c}
I_{L}+\hat{\imath}_{L} \\
V_{c}+\hat{v}_{c}
\end{array}\right]+\left[\begin{array}{cc}
\frac{1}{L} & {\left[\frac{D}{L}-\frac{1}{L}+\frac{\hat{d}}{L}\right]} \\
0 & 0
\end{array}\right]\left(V_{I}+\hat{v}_{I}\right)} \\
& {\left[\begin{array}{c}
\hat{\imath}_{L} \\
\dot{\hat{v}}_{c}
\end{array}\right]=\left[\begin{array}{cc}
{\left[\left(-\frac{R_{p}}{L}+\frac{R_{m}}{L}\right) D-\frac{R_{m}}{L}\right]} & {\left[\frac{R_{t}}{L} D-\frac{R_{t}}{L}\right]} \\
{\left[-\frac{R_{t}}{C} D+\frac{R_{t}}{C}\right]} & {\left[-\frac{R_{t}}{C R_{o}}\right]}
\end{array}\right]\left[\begin{array}{l}
I_{L} \\
V_{c}
\end{array}\right]+} \\
& {\left[\begin{array}{cc}
{\left[\left(-\frac{R_{p}}{L}+\frac{R_{m}}{L}\right) D-\frac{R_{m}}{L}\right]} & {\left[\frac{R_{t}}{L} D-\frac{R_{t}}{L}\right]} \\
{\left[-\frac{R_{t}}{C} D+\frac{R_{t}}{C}\right]} & {\left[-\frac{R_{t}}{C R_{o}}\right]}
\end{array}\right]\left[\begin{array}{c}
\hat{\imath}_{L} \\
\hat{v}_{c}
\end{array}\right]+\left[\begin{array}{cc}
\left(\frac{R_{m}}{L}-\frac{R_{p}}{L}\right) \hat{d} & \frac{R_{t}}{L} \hat{d} \\
-\frac{R_{t}}{C} \hat{d} & 0
\end{array}\right]\left[\begin{array}{l}
I_{L} \\
V_{c}
\end{array}\right]+\left[\begin{array}{cc}
\left(\frac{R_{m}}{L}-\frac{R_{p}}{L}\right) \hat{d} & \frac{R_{t}}{L} \hat{d} \\
-\frac{R_{t}}{C} \hat{d} & 0
\end{array}\right]\left[\begin{array}{c}
\hat{\imath}_{L} \\
\hat{v}_{c}
\end{array}\right]+\left[\begin{array}{cc}
\frac{1}{L} & \frac{D}{L}-\frac{1}{L} \\
0 & 0
\end{array}\right]\left[\begin{array}{c}
V_{I}+\hat{v}_{I} \\
V_{f}+\hat{v}_{f}
\end{array}\right]+} \\
& {\left[\begin{array}{ll}
0 & \frac{\hat{d}}{L} \\
0 & 0
\end{array}\right]\left[\begin{array}{l}
V_{I}+\hat{v}_{I} \\
V_{f}+\hat{v}_{f}
\end{array}\right]}
\end{aligned}
$$

If the terms $\hat{d} \hat{v}_{I} \approx 0$, and $\hat{v}_{f}=0$ are neglected the steady-state parts are equal to zero as stated before (AX+BU=0). Therefore:

$$
\begin{aligned}
& {\left[\begin{array}{c}
\hat{\imath}_{L} \\
\dot{\hat{v}}_{c}
\end{array}\right]=\left[\begin{array}{cc}
{\left[\left(-\frac{R_{p}}{L}+\frac{R_{m}}{L}\right) D-\frac{R_{m}}{L}\right]} & {\left[\frac{R_{t}}{L} D-\frac{R_{t}}{L}\right]} \\
{\left[-\frac{R_{t}}{C} D+\frac{A_{t}}{C}\right]} & -\frac{R_{t}}{C R_{O}}
\end{array}\right]\left[\begin{array}{c}
\hat{\imath}_{L} \\
\hat{v}_{c}
\end{array}\right]+\left[\begin{array}{c}
\left(\frac{R_{m}}{L}-\frac{R_{p}}{L}\right) I_{L}+\frac{R_{t}}{L} V_{c} \\
-\frac{R_{t}}{C} I_{L}
\end{array}\right] \hat{d}+\left[\begin{array}{c}
\frac{1}{L} \\
0
\end{array}\right]\left[\begin{array}{c}
\hat{v}_{I} \\
0
\end{array}\right]} \\
& \hat{v}_{o}=\left[\begin{array}{ll}
r_{c} R_{t}(1-D) & R_{t}
\end{array}\right]\left[\begin{array}{l}
\hat{\imath}_{L} \\
\hat{v}_{c}
\end{array}\right]
\end{aligned}
$$

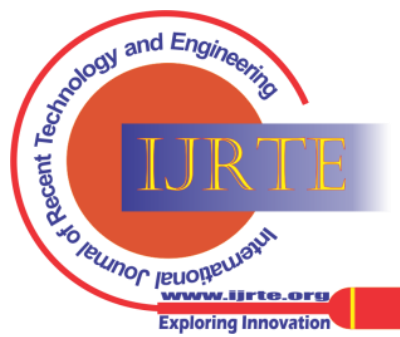


Again, for the small-signal $\hat{d}$ to output $\hat{v}_{o}$, the transfer function can be determined as:

$$
\begin{gathered}
\left.\frac{\hat{v}_{o}}{\hat{d}}(s)\right|_{\hat{v}_{I}=0}=\text { control voltage gain }=C(S I-A)^{-1}\left(B_{1}+B_{2}\right) \\
\hat{v}_{o}=\left[\begin{array}{ll}
r_{c} R_{t}(1-D) & R_{t}
\end{array}\right]\left[\begin{array}{cc}
s+\frac{R_{m}}{L}(1-D)+\frac{R_{p}}{L} D & \frac{R_{t}}{L}(1-D) \\
\frac{R_{t}}{C}(D-1) & s+\frac{R_{t}}{C R_{o}}
\end{array}\right] \\
{\left[\begin{array}{cc}
\left(\frac{R_{m}}{L}-\frac{R_{p}}{L}\right) I_{L}+\frac{R_{t}}{L} V_{c} & \frac{1}{L} \\
-\frac{R_{t}}{C} I_{L} & 0
\end{array}\right]\left[\begin{array}{l}
\hat{d} \\
\hat{v}_{I}
\end{array}\right]}
\end{gathered}
$$

The determinant of the matrix $\left|A_{s}\right|$, can be found as:

$$
\begin{gathered}
\left|A_{d}\right|=s^{2}+\left[\frac{R_{t}}{C R_{o}}+\frac{R_{m}}{L}(1-D)+\frac{R_{p}}{L} D\right] s+\left[\frac{R_{m} R_{t}}{L C R_{o}}(1-D)+\frac{R_{p} R_{t}}{L C R_{o}} D+\frac{R_{t}^{2}}{L C}(1-D)^{2}\right] \\
=\frac{\left[r_{c} R_{t}(1-D) R_{t}\right]}{\left|A_{d}\right|}\left[\begin{array}{c}
\left(s+\frac{R_{t}}{C R_{o}}\right)\left[\left(\frac{R_{m}}{L}-\frac{R_{p}}{L}\right) I_{L}+\frac{R_{t}}{L} V_{c}\right]+\frac{R_{t}^{2}}{L C}(1-D) I_{L} \\
-\frac{R_{t}}{C}(D-1)\left[\left(\frac{R_{m}}{L}-\frac{R_{p}}{L}\right) I_{L}+\frac{R_{t}}{L} V_{c}\right]+\left[s+\frac{R_{m}}{L}(1-D)+\frac{R_{P} D}{L}\right]\left(-\frac{R_{t}}{C} I_{L}\right)
\end{array}\right]
\end{gathered}
$$

Then, the equation that represents the dynamics are

$\frac{\hat{v}_{o}}{\hat{d}}=\frac{r_{C} R_{t}(1-D)\left[\left(s+\frac{R_{t}}{C R_{o}}\right)\left[\left(\frac{R_{m}}{L}-\frac{R p}{L}\right) I_{L}+\frac{R_{t}}{L} V_{C}\right]+\frac{R_{t}^{2}}{L C}(1-D) I_{L}\right]+R_{t}\left[-\frac{R_{t}}{C}(D-1)\left[\left(\frac{R_{m}}{L}-\frac{R_{p}}{L}\right) I_{L}+\frac{R_{t}}{L} V_{C}\right]+\left[s+\frac{R_{m}}{L}(1-D)+\frac{R_{P} D}{L}\right]\left(-\frac{R_{t}}{C} I_{L}\right)\right]}{s^{2}+\left[\frac{R_{t}}{C R_{O}}+\frac{R_{m}}{L}(1-D)+\frac{R p}{L} D\right] s+\left[\frac{R_{m} R_{t}}{L C R_{O}}(1-D)+\frac{R_{p} R_{t}}{L C R_{O}} D+\frac{R_{t}^{2}}{L C}(1-D)^{2}\right]}$

where,

$R_{m}=\frac{\left(r_{L}+r_{f}\right)\left(R_{o}+r_{c}\right)+r_{c} R_{o}}{\left(R_{o}+r_{c}\right)}$

$R_{p}=r_{L}+r_{D S}$

$R_{t}=\frac{R_{o}}{\left(R_{o}+r_{c}\right)}$

\section{Boost converter control strategy:}

The boost converter must provide a regulated output voltage irrespective of variation in the perturbations in the dynamics parameters [39]. Hence, the control design must be confined to the closed-loop method using the principle of feedback. Two standard methods can be used, known as voltage-mode and current-mode control. In this project, some of the findings of empirical research into digital controller design are presented, which depend on voltage-mode control. In the voltage-mode control block diagram shown in Figure 6 the voltage is measured using voltage divider resistors connected parallel on the load side, and the signal is digitally processed by sampling the feedback using the microcontroller to subtract the result from the desired reference voltage. This arithmetic subtraction results in error which relates to a constant amplitude first-class waveform called the frequency carrier. Boost converters are complex in terms of control in relation to the buck converter because from the transfer function a positive zero appears in the right half-plane RHP. An assessment of system is carried out in this project to validate the transfer function using the simulation software MATLAB/Simulink, and then comparing it with the result of experimental testing. The methodology of closed-loop control is designed for the control of the boost converter based on state-space model analysis taken into consideration the drawbacks of nonminimum phase behaviur which thus impact on

performance. However, real-time implementation encounters many limitations in many aspects in order to keep the system stable and more robust. A software algorithm is designed to compare the feedback signal with the desired input voltage in order to produce an error-index signal to control the small-signal duty cycle $\hat{d}[40]$.

The digital counter in the microcontroller generates a repeating sequence of counting-up from0 to 1023 and then counting-down from 1023 to 0 . The pulse width modulation is produced by comparing the counter stored in the register to the modulation index error and then updating the smallsignal duty cycle $\hat{d}[41]$.

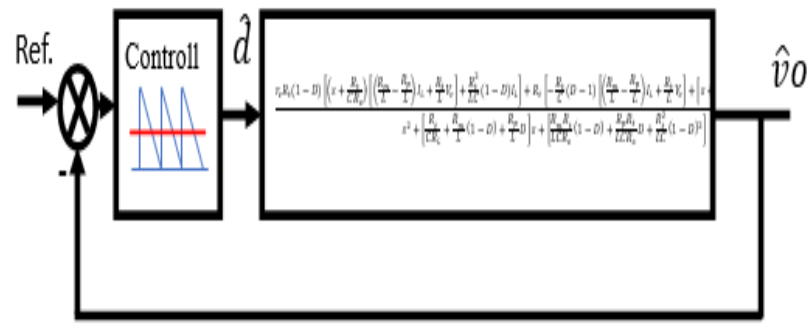

Figure 6: Block diagram of linearized boost converter

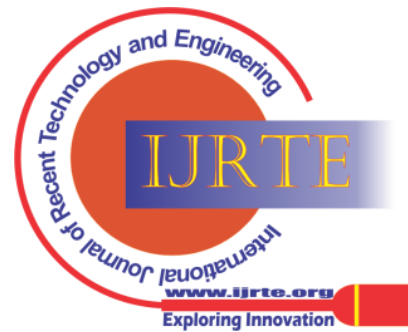




\section{Cloud-based IoT Platform DC-DC Power Converter (Non-Ideal)}

\section{RESULTS \& DISCUSSIONS}

This chapter discusses in detail the results for the PWM DCDC converter, which are divided into; those from the simulations analysis and the real experimental implementation. However, it is important to bear in mind that the output are based on the convergences in the specifications and possible parameters for the virtual simulation and the real implementation. The plan is to validate the results in the simulation and then to compare them it with the measurements taken from a printed circuit board (PCB) with real components. Therefore, the non-ideal impact of these components must be taken into account. The main purpose of this study is to develop a deeper understanding of the effect of perturbations in the input line voltage and output load, where the converter has been subject to simulated and experimentation in two different modes of operation. The first set of tests focused mainly on a virtual analysis using MATLAB /SIMULINK. The subsequent tests were conducted in order to prove the accuracy of transfer function from the state-space average modeling and how the parasitics affect performance. The next tests were concentrated on the open-loop response for a fixed duty cycle. Finally, the digital PI controller was implemented in a closed-loop voltage mode control system using the popular $\mathrm{C}$ programming language. The limitations of the study and the solutions proposed to improve the reasearch are also discussed in this chapter. Simulation: The PWM DC-DC converter was simulated numerically in SIMULINK, as shown in Figure 7.

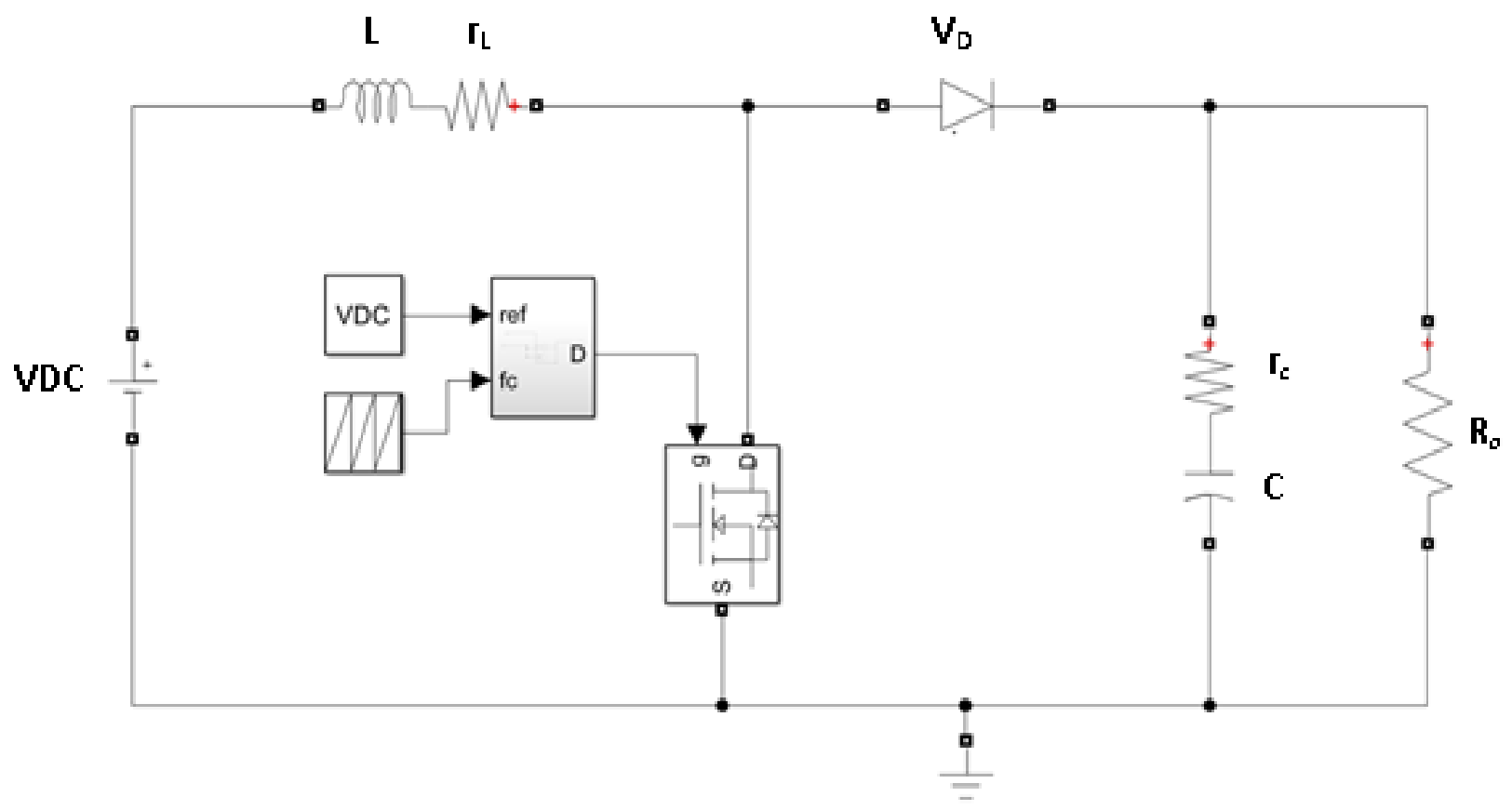

Figure 7:Boost converter build in powergui (G0)

The parameters associated with the converters corresponding to SIMULINK parameter names are shown in Table 1:

Table 1: Simulation parameters

\begin{tabular}{|c|c|l|}
\hline Parameter & Value & \multicolumn{1}{|c|}{ Description } \\
\hline fs & $80 \mathrm{kHz}$ & Carrier frequency \\
\hline Lmin & $220 \mathrm{uH}$ & Inductor value \\
\hline $\mathrm{rL}$ & $0.055 \Omega$ & Equivelant series resistor ESR of inductor \\
\hline $\mathrm{rds}$ & $0.077 \Omega$ & FET resistance Ron \\
\hline $\mathrm{rf}$ & $0.0328 \Omega$ & Forward resistor of diode (Figure 1-24) \\
\hline $\mathrm{Vf}$ & $0.5 \mathrm{~V}$ & Forward voltage \\
\hline $\mathrm{rc}$ & $0.307 \Omega$ & Equivelant series resistor ESR of capacitor \\
\hline $\mathrm{C}$ & $330 \mathrm{uF}$ & Capacitor value \\
\hline Ro & $28.2 \Omega$ & Lad Resistor [Ro(Nom)=48 $\Omega$ ] \\
\hline VDC & $5.0 \mathrm{~V}$ & Input line voltage [Vo(Nom.)=5 V] \\
\hline $\mathrm{d}$ & 0.625 & input reference [d(Nom.)=0.63] \\
\hline
\end{tabular}


The model of the boost converter works using a DC power supply with a fixed duty cycle and pulse width modulation (PWM). During the simulation, the parameters of the power supply were altered in order to understand the behaviur of test:

\section{Simulation:}

The frequency carrier was configured to generate a frequency of $80 \mathrm{kHz}$ and the amplitude was varied from 0 to 1 , as illustrated in Figure 8. The index reference of the input was set to 0.625 , corresponding to $62.5 \%$ of the duty cycle. The output resistive load was set to $28.2 \Omega$ in order to match the system with the real converter. The output waveforms produced from the boost converter of the powergui (G0) system are presented in Figure 7. It was observed that the output voltage converges to $12.6 \mathrm{~V}$ at $10 \mathrm{~ms}$, and the output gain is reached until an overshoot occurs which can be calculated as follows: Mover $_{\text {shoot }} \%=\frac{16-12.45}{12.45}=29 \%$

The output voltage waveform was found to fluctuate around the average value due to the effect of the pulse width modulation PWM produced from microcontroller. This leads the inductor to store the energy temporarily, and then release it within the limits of inductance value by turning the semiconductor switch $\mathrm{ON}$ and OFF. A mentioned in the literature, this method is widely used due to its capability to shape the output waveform to any desired value. Moreover, the PWM boost converter maintains high efficiency; however, it should be taken into consideration that switching produces plenty of harmonics which eventually affect the overall performance. The working principle is determined by comparing the input reference ' $d$ ' with the counter value that represents the 900 right triangle of the frequency carrier as illustrated in Figure 38, and then the relational operator has the responsibility for the arithmetic decision. As a result, if the value of the right triangle is lower than the input reference ' $d$ ' then the relational function output gives logic 1 , and if it is greater than ' $\mathrm{d}$ ' it will turn to logic 0 as shown in Figure 8:
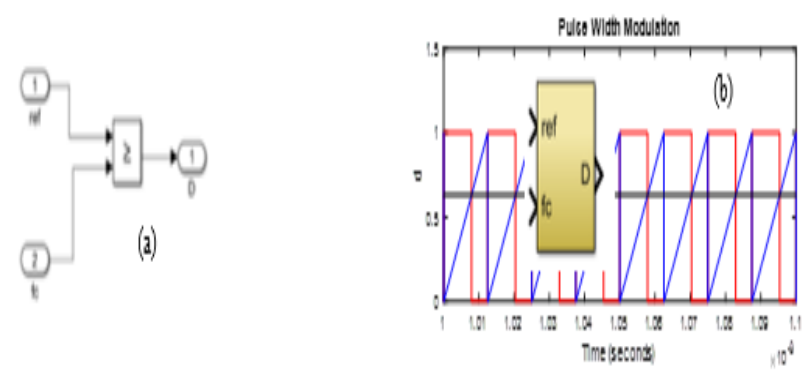

Figure 8: Pulse wide modulation: (a) Simulink block diagram, and (b) Input reference $d$ related to frequency carrier.

The effect of modifying the input reference ' $d$ ' was investigated. Hence, the input reference ' $d$ ' value was changed from 0.1 to 0.9 and increases in output voltage $\mathrm{Vo}_{0}$ and output current IL were observed as the input value increased for a fixed load resistance Ro as shown in Figure 9. the converter's output response in the subsequent simulation

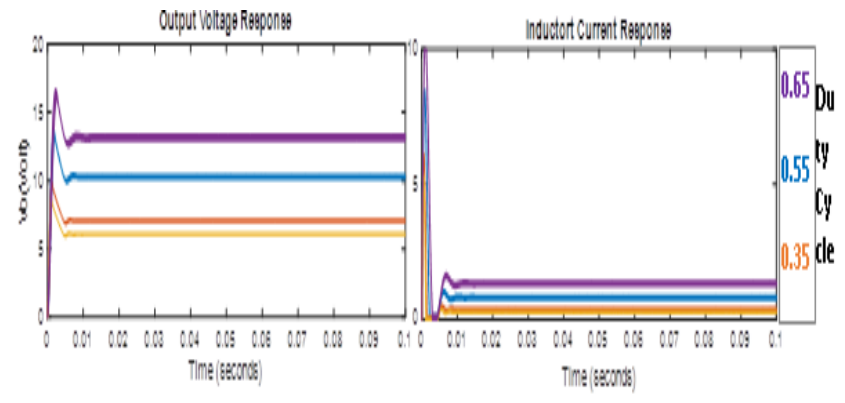

Figure 9: Output responses with different value of duty cycle per time (s)

Further investigation has been carried out in order to understand the behaviur of the output response when the inductance value is changed from $1000 \mu \mathrm{H}$ to $10 \mu \mathrm{H}$, as shown in Figure 10. The impact of reducing the inductance was directly affecting the oscillation around the average because the time constant is proportional to the inductance value $\mathrm{T}=\frac{L}{R}$, which means that it takes a long time to reach the steady-state. Also, the current increased drastically. This was because due to the inductance in the circuit is inversely

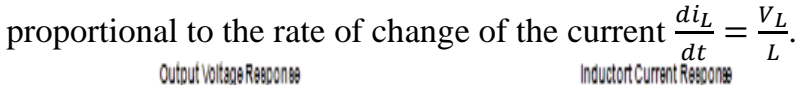
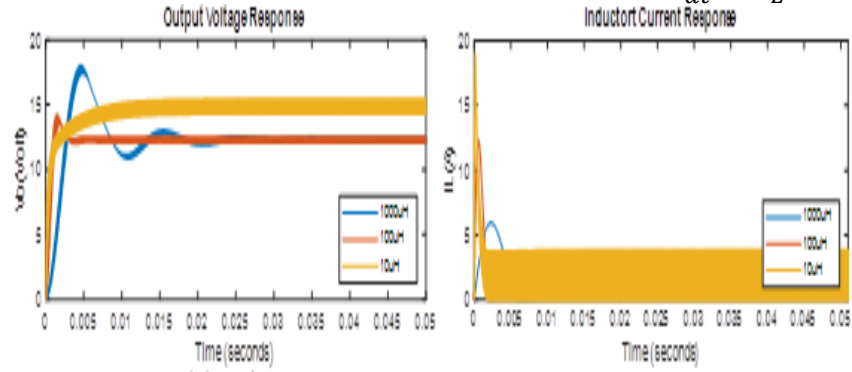

Figure 10: The voltage and current response of with different value of duty cycle per Time

When the inductance was reduced to $10 \mu \mathrm{H}$, the inductor current reached the boundary and equalled zero for a small period as shown in Figure 11. As mentioned before, the converter operates in discontinuous conduction mode (DCM). Therefore inductance is critical and should design specifically for each mode of operation.

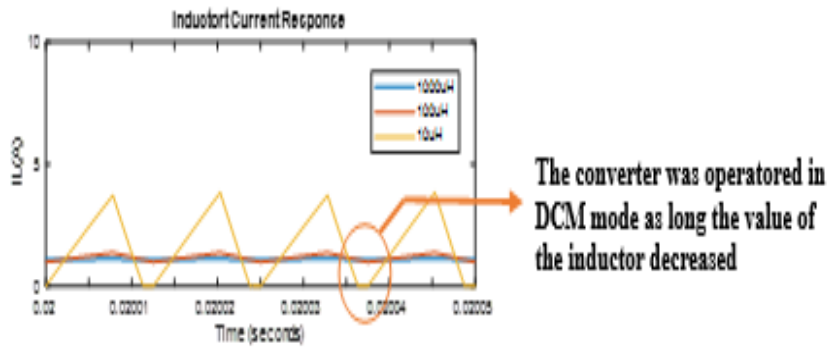

Figure 11: Discontinuous conduction mode DCM

The output capacitance was changed to different values from $1 \mu \mathrm{F}$ to $1000 \mu \mathrm{F}$. The results of the change were observed in the ripple voltage, as shown in Figure 12,which increased as the capacitance value decreased.

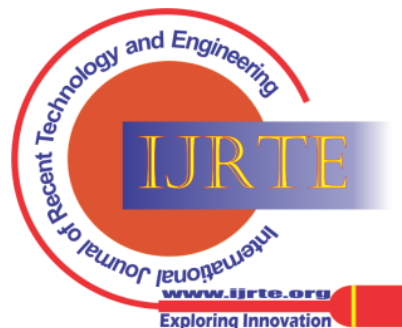


Cloud-based IoT Platform DC-DC Power Converter (Non-Ideal)
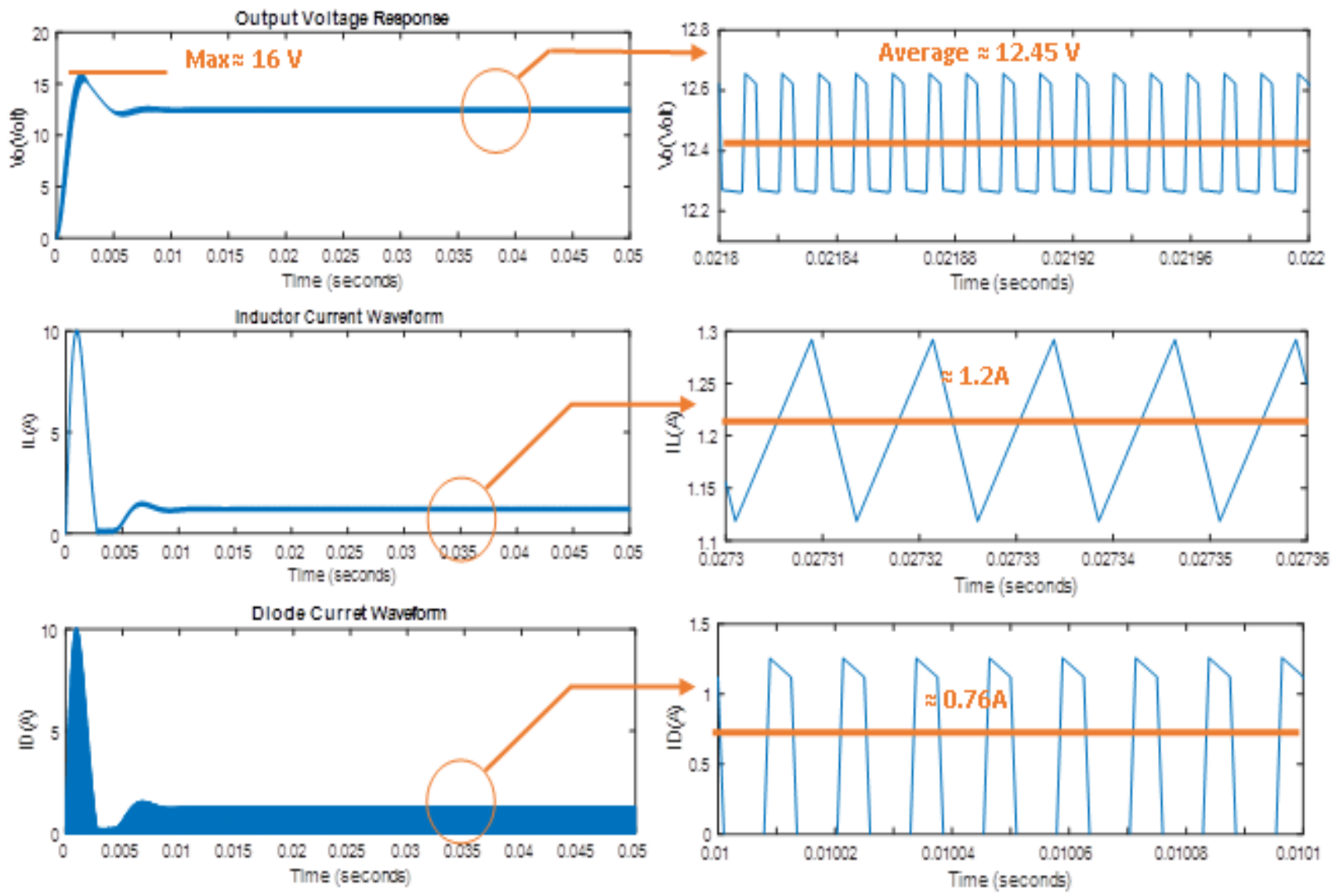

Figure 12: Boost Converter output waveforms

Small signal average transfer function $\frac{V_{o}}{\widehat{d}}$ :

Case1: ideal system:

Substituting the below data into equation $\frac{V_{o}}{\widehat{d}}$ yields:

\begin{tabular}{|l|l|l|l|}
\hline Ro & L & C & d \\
\hline 28.2 & $2.20 \mathrm{E}-04$ & $3.30 \mathrm{E}-04$ & 0.625 \\
\hline
\end{tabular}

$G_{1}=\frac{\hat{v}_{O}}{\hat{d}}=\frac{-3821 s+6.887 e 7}{s^{2}+107.5 s+1.937 e 6}$

Following Figures 13 were simulated take into consideration for ideal case boost converter in idealize condition. The system (G1) was stable since the poles in the left-hand plane with a complex part which is the main reason of the high oscillation appeared on the output response of the average small signal (G1). This means that the system is underdamped, and this behavior can be confirmed by checking the discriminant equation $\mathrm{A} 2<4 \mathrm{~B}$. moreover, it was seen that performs non-minimal phase characteristics due to the right half-plane (RHP) zero. Due to this term, an initial dip was observed as shown in Figure 14. The dynamics characteristics compression between G0 and G1 can be found in the following Table 2 :

Table 1: dynamics characteristics of G0 and G1

\begin{tabular}{|c|c|c|c|c|c|}
\hline & $\mathbf{t}_{\mathbf{s} \text { Min }}(\mathbf{s})$ & $\mathbf{t}_{\mathbf{s} \text { Max }}(\mathrm{s})$ & $\mathbf{t}_{\mathbf{s}}(\mathbf{s})$ & Pole's & Zero's \\
\hline $\mathbf{G}_{0}$ & 0.5748 & 5.028 & 0.0725 & none & $-53.7 \pm \mathrm{j} 1.39 \mathrm{e} 3$ \\
\hline $\mathbf{G}_{1}$ & 7.6736 & 67.04 & 0.0725 & $1.82 \mathrm{e} 4$ & $-53.7 \pm \mathrm{j} 1.39 \mathrm{e} 3$ \\
\hline
\end{tabular}

As seen in the above Table 2, the time delay was introduced in G1 in contrast with G0, which means that G1 has lower stability margin as the output response take longer time to settle and reach to steady-state. Furthermore, obtaining a high voltage gain with this type of system characteristics may leading to destabilization. It is usually hard to design a controller to deal with this situation because of the poles in the close-loop get attracted to the right-hand plane RHP as the gain voltage increase $[4,35]$. Broadly speaking, at low resistance and high-gain applications the zero of RHP is shifted to the imaginary axis; this means that the feedback controllers become more sophisticated to design. However, design a controller is basically depends on the designers how acceptable phase margin the interested to achieve [51].

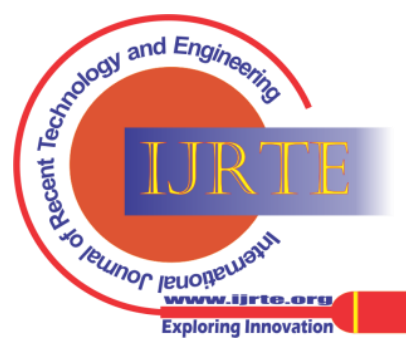



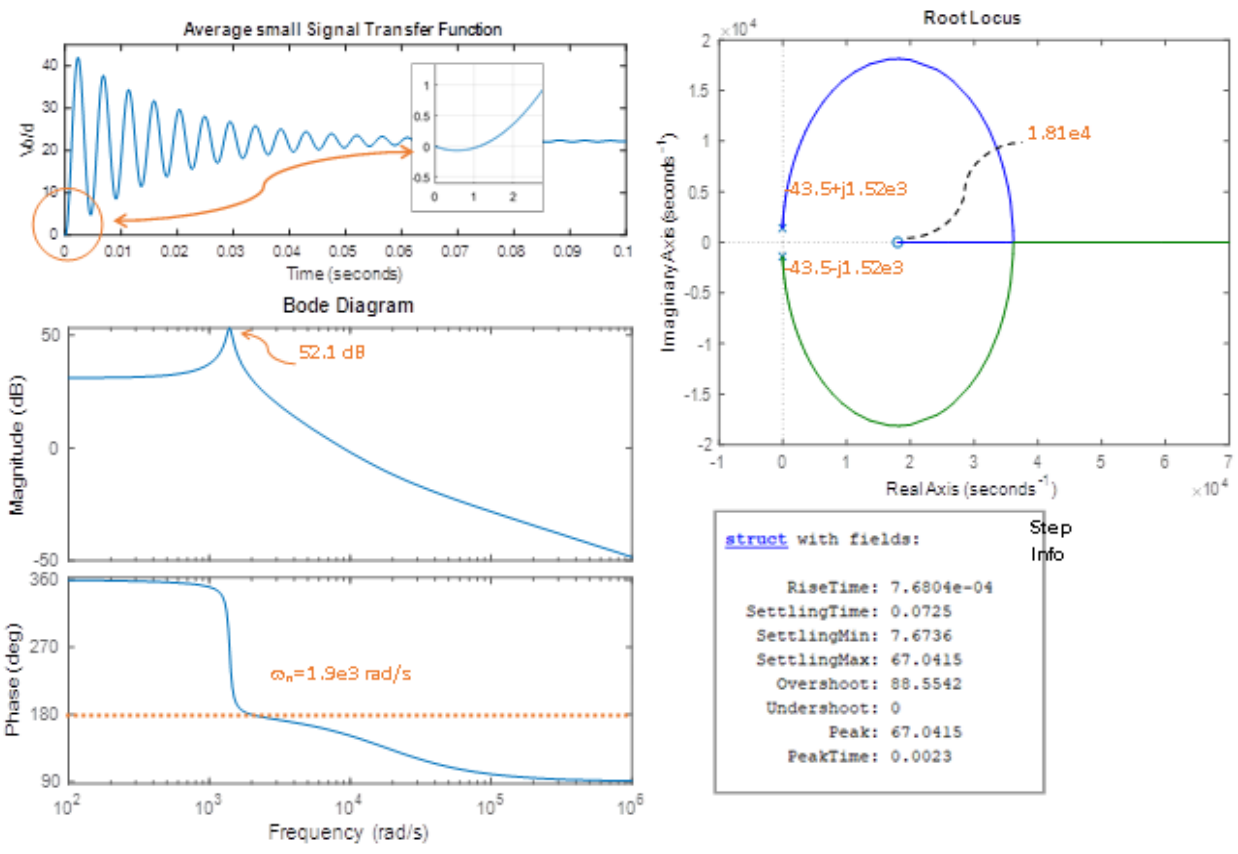

Figure 14: Transient characteristics of G2

Case2: non-ideal system:

The same test was simulated, but with considering the parasitics, as follow:

\begin{tabular}{|c|c|c|c|c|c|c|c|c|}
\hline Ro & rds & rf & Vf & L & rL & C & rc & d \\
\hline 28.2 & 0.077 & 0.0328 & 0.5 & $2.20 \mathrm{E}-04$ & 0.055 & $3.30 \mathrm{E}-04$ & 0.307 & 0.625 \\
\hline
\end{tabular}

Substituting the below data into equatioin $\frac{V_{\boldsymbol{o}}}{\hat{d}}$ in order to determine the small-signal averager transfer function $G 3=\frac{\hat{v}_{o}}{\hat{d}}=\frac{2816 s+5.828 e 7}{s^{2}+1149 s+2.006 e 6}$

The small average signal model G3 was simulated with all possible uncertainties. The transient characteristics results of G3 were found as shown in Figure 15. The effect of the parasitics was observed, where the oscillation is drastically decreased. The overshoot drop from $88.6 \%$ to $24.86 \%$.
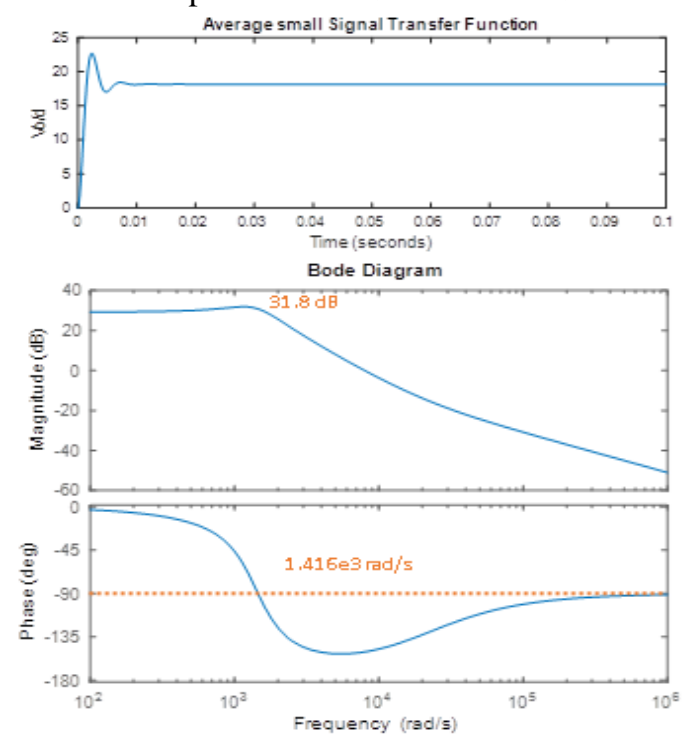

Also, the s-plane graph showed that the system was stable with less oscillation compare to $\mathrm{G} 1$, because of the real part of the zero is negative with less value complex number, that means the system is stable with slightly less oscillation compared with G1. Moreover, the poles of the G3 transfer function move far away to the left-hand plane, which means the initial dip in the start has been removed, and the converter functions as a first-order system. Figure 51 shows the output of the simulation.

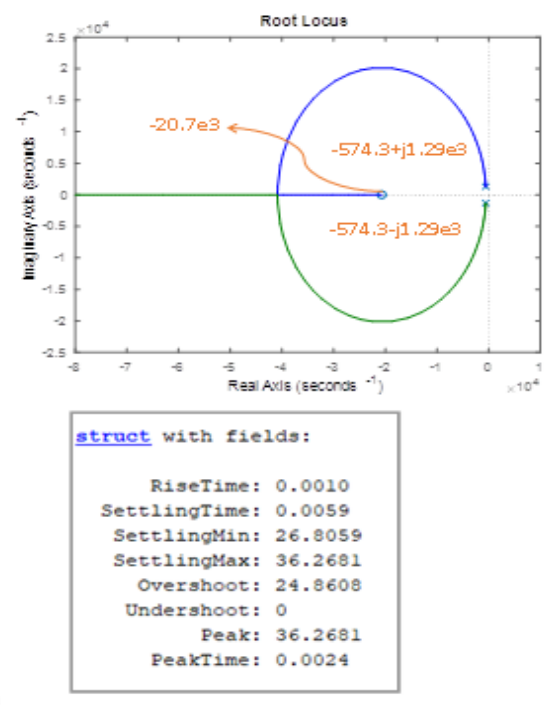

Figure 15: Transient characteristics of G4

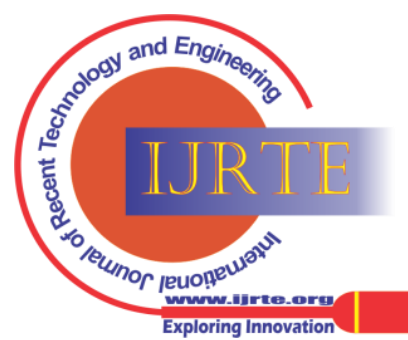




\section{Cloud-based IoT Platform DC-DC Power Converter (Non-Ideal)}

The dynamics characteristics compression between G1 and G3 can be found in the following comparsion Table 3:

Table 2: Transient characteristics summary of average large-signal modeling G3 and G5

\begin{tabular}{|c|l|l|l|l|l|l|l|}
\hline$\frac{\mathbf{V}_{0}}{\bar{d}}$ & $\mathbf{t}_{\mathbf{p}}(\mathrm{s})$ & $\mathbf{t}_{\mathbf{s}}(\mathrm{s})$ & $\mathbf{M}_{\mathrm{p}} \%$ & $\begin{array}{c}\boldsymbol{\omega}_{\mathbf{n}} \\
(\mathrm{rad} / \mathrm{s})\end{array}$ & $\zeta$ & Pole's & Zero's \\
\hline $\mathbf{G}_{\mathbf{1}}$ & 0.0023 & 0.0725 & 88.6 & $1.39 \mathrm{e} 3$ & 0.0386 & $18.02 \mathrm{e} 3$ & $\begin{array}{l}-53.7 \pm \\
j 1.39 \mathrm{e} 3\end{array}$ \\
\hline $\mathbf{G}_{3}$ & 0.0024 & 0.0059 & 24.86 & $1.42 \mathrm{e} 3$ & 0.405 & $-20.7 \mathrm{e} 3$ & $\begin{array}{l}-574.3 \pm \\
\mathrm{j} 1.29 \mathrm{e} 3\end{array}$ \\
\hline
\end{tabular}

The linearized transfer function was simulated with considering all possible uncertainties to obtain the accuracy of the model for the transient analysis and make the designer in better position to design take decision to design the controller. Hence, the small-signal average model was determined around the equilibrium point will be used to develop the proportional-integral PI. In this model, the elements assumed to be close to real values as much as possible to keep the reliability and validity high.

\section{CONCLUSION}

- A Simulink simulation of the design of the boost dc-dc converter was validated through comparing them with the experimental results.

- The boost-converter was successfully monitored through integrating it with the IOT cloud.

- The implementation of $\mathrm{C} / \mathrm{C}++$ programming codes of the PI controller was perfectly excellent at disturbance rejection, hence stabilizing the voltage level according to the demanding value.

\section{REFERENCES}

1. M. H. Rashid, Power Electronics Handbook, 4th ed. 2017.

2. M. K. Kazimierczuk, Pulse-width modulated DC-DC power converters. Chichester : John Wiley \& Sons, Ltd., 2008.

3. S. Verma, S. K. Singh, and A. G. Rao, "Overview of control Techniques for DC-DC converters," Research Journal of Engineering Sciences vol. 2, no. 8, pp. 18-21, 2013.

4. M. Forouzesh, Y. P. Siwakoti, S. A. Gorji, F. Blaabjerg, and B Lehman, "Step-Up DC-DC Converters: A Comprehensive Review of Voltage-Boosting Techniques, Topologies, and Applications.," IEEE Transactions on Power Electronics, vol. 32, no. 12, pp. 9143 9178, 2017

5. S. Saravanan and N. Babu, "Design and Development of Single Switch High Step-Up DC-DC Converter," IEEE Journal of Emerging and Selected Topics in Power Electronics, vol. 6, no. 2, pp. 855-863, 2018 .

6. F. S. Alargt, A. S. Ashur, and A. H. Kharaz, "Performance comparison between PWM and SSDM techniques in interleaved boost converter," in 2015 50th International Universities Power Engineering Conference (UPEC), Stoke on Trent, 2015.

7. A. Babazadeh and D. J. Tschirhart, "Adaptive dynamic voltage Electronics, vol. 11, no. 3, pp. 507-514, 2018.

8. S. Zabihi, F. Zare, G. Ledwich, A. Ghosh, and H. Akiyama, "A New Generation of High Voltage Pulsed Power Converters," presented at the 2010 20th Australasian Universities Power Engineering Conference, 2010.

9. B. W. , S. L. , K. Ma Smedley, and S. Singer, "A Family of TwoSwitch Boosting Switched-Capacitor Converters," IEEE Transactions on Power Electronics, vol. 30, no. 10, pp. 5413-424, 2015 .

10. G. , K. and H. , A, "On the modelling of DC-DC converters: An enhanced approach," International Journal of Numerical Modelling, transitioning in switch mode DC-DC power converters," IET Powe

vol. 24, no. 1, pp. 36-57, 2011.

11. M. Elsaharty, H. Ashour, E. Rakhshani, E. Pouresmaeil, and J. Catalão, "A Novel DC-Bus Sensor-less MPPT Technique for SingleStage PV Grid-Connected Inverters.," Energies, vol. 9, no. 4, p. 248, 2016.

12. S. Hayashi and M. Yamada, "EMI-noise analysis under ASIC design environment," IEEE Transactions on Computer-Aided Design of Integrated Circuits and Systems, vol. 19, no. 11, pp. 1337-1346, 2000 .

13. B. Axelrod and Y. Berkovich, "New coupled-inductor SEPIC converter with very high conversion ratio and reduced voltage stress on the switches," in 2011 IEEE 33rd International Telecommunications Energy Conference (INTELEC), Amsterdam, 2011.

14. J. M. Enrique, A. J. Barragán, E. Durán, and J. M. Andújar, "Theoretical Assessment of DC/DC Power Converters' Basic Topologies. A Common Static Model," vol. 8, no. 1, p. 19, 2017.

15. M. Khan, A. Ahmed, I. Husain, Y. Sozer, and M. Badawy, "Performance Analysis of Bidirectional DC-DC Converters for Electric Vehicles," IEEE Transactions on Industry Applications, vol. 51, no. 4, pp. 3442-3452, 2015.

16. B. C. , J. N. , H. C. , T. A., and S. C. , "Design and implementation of low-profile contactless battery charger using planar printed circuit board windings as energy transfer device," IEEE Transactions on Industrial Electronics, vol. 51, no. 1, pp. 140-147, 2004.

17. I. Yazici, A. Ozdemir, and Z. Erdem, "Real time implementation of a digital controlled boost converter," in 2009 International Conference on Electrical and Electronics Engineering, Bursa, 2009.

18. B. Abdelhamid, L. Radhouane, and A. Bilel, "Real time implementation of perturb and observe algorithm and PI controller for DC/DC converter," in 2017 18th International Conference on Sciences and Techniques of Automatic Control and Computer Engineering (STA), Monastir, 2017.

19. D. Ahmed, "Properties of transfer function. ," 2014.

20. K. Hariharan and S. Kapat, "Need for variable frequency control in DC-DC switching converters - Challenges and opportunities using digital implementation," Proceedings of the Indian National Science Academy, vol. 84, no. 3, pp. 657-668, 2018.

21. M. R. Modabbernia, A. R. Sahab, M. T. Mirzaee, and K. Ghorbany, "The State Space Average Model of Boost Switching Regulator Including All of the System Uncertainties," Advanced Materials Research, vol. 403-408, pp. 3476-3483, 2012.

22. A. Özdemir and Z. Erdem, " Double-loop PI controller design of the DC-DC boost converter with a proposed approach for calculation of the controller parameters. Proceedings of the Institution of Mechanical Engineers," Part I: Journal of Systems and Control Engineering, vol. 232, no. 2, pp. 137-148, 2018.

23. C. Chen et al., "Online Inductor Parameters Identification by SmallSignal Injection for Sensorless Predictive Current Controlled Boost Converter," IEEE Transactions on Industrial Informatics, vol. 13, no. 4, pp. 1554-1564, 2017.

24. L. Cheng et al., "Model Predictive Control for DC-DC Boost Converters With Reduced-Prediction Horizon and Constant Switching Frequency," IEEE Transactions on Power Electronics, vol. 30, no. 10, pp. 9064-9075, 2018. 
25. Machura and N. Li Ying, "A Critical Review on Wireless Charging for Electric Vehicles," Renewable and Sustainable Energy Reviews, vol. 104, pp. 209-234, 2019.

26. J. C. Hertel, Y. Nour, and A. Knott, "Integrated Very-HighFrequency Switch Mode Power Supplies: Design Considerations," IEEE Journal of Emerging and Selected Topics in Power Electronics, vol. 6, no. 2, pp. 526-538, 2018.

27. C.-M. Lai, "Development of a Novel Bidirectional DC/DC Converter Topology with High Voltage Conversion Ratio for Electric Vehicles and DC-Microgrids," Energies, vol. 9, no. 6, p. 410, 2016.

28. A. Bousbaine and M. Eljarh, "Development of a novel $5 \mathrm{~kW} / 42 \mathrm{~V}$ intelligent converter for automotive applications," in 6th IET International Conference on Power Electronics, Machines and Drives (PEMD 2012), Bristol, UK, 2012.

29. R. Naayagi, A. J. Forsyth, and R. Shuttleworth, "High-Power Bidirectional DC-DC Converter for Aerospace Applications," IEEE Transactions on Power Electronics vol. 27, no. 11, pp. 4366 - 4379 , 2012

30. I. Das and T. Roy, "A new multi-device boost converter topology with reduced switching stress and high voltage gain," in Michael Faraday IET International Summit 2015, vol. 2015, no. 683, pp. 380-386, 2015

31. Paduvalli, V. V, R. J. Taylor, L. R. Hunt, and P. T. Balsara, "Mitigation of Positive Zero Effect on Nonminimum Phase Boost DC-DC Converters in CCM," IEEE Transactions on Industrial Electronics, vol. 65, no. 5, pp. 4125-4134, 2018.

32. Cunha and Pagano., "LIMITATIONS IN THE CONTROL OF A DC-DC BOOST CONVERTER," IFAC Proceedings Volumes, vol. 35, no. 1, pp. 211-216, 2002

33. Dash and Nayak, "Control Analysis and Experimental Verification of a Practical Dc-dc Boost Converter," 2015, vol. 2.3, no. 2015, pp. 378-90, 2015

34. Lopez-Santos et al., "Steady-State Analysis of Inductor Conduction Modes in the Quadratic Boost Converter," Ieee Transactions On Power Electronics, vol. 32.3, no. 2017, pp. 2253-264, 2017.

35. E. W. Robert, Fundamentals of power electronics. New York: Chapman \& Hall, 1997.

36. J. Sun, D. Mitchell, M. Greuel, P. Krein, and R. Bass, "Averaged Modeling of PWM Converters Operating in Discontinuous Conduction Mode," Ieee Transactions On Power Electronics vol. 16.4, no. 2001, pp. 482-92, 2001.

37. G. A. Covic and J. T. Boys, "Inductive Power Transfer," Proceedings of the IEEE, vol. 101, no. 6, pp. 1276-1289, 2013.

38. J. B. Hag, Bernstein, and D.S., "Nonminimum-phase zeros - much to do about nothing - classical control - revisited part II," IEEE Control Systems, vol. 27, no. 3, pp. 45-57, 2007.

39. Martinez-Trevino, B. Areli, A. E. Aroudi, A. Cid-Pastor, and L. Martinez-Salamero., "Nonlinear Control for Output Voltage Regulation of a Boost Converter with a Constant Power Load," IEEE Transactions on Power Electronics PP, vol. 99, no. 2019, p. 1, 2019.

40. Arora, Sameer, P. Balsara, and D. Bhatia, "Input-Output Voltage Load and Constant Power Load)," IEEE Transactions on Power Electronics, vol. 34, no. 1, pp. 815-825, 2019.

41. Jasielsk, Jacek, S. Kuta, W. Kolodziejski, and W. Machowski, "Hybrid LBDD PWM Modulator for Digital Class-BD Audio Amplifier Based on STM32F407VGT6 Microcontroller and Analog DLL," 2015 22nd International Conference Mixed Design of Integrated Circuits \& Systems (MIXDES), no. 2015, pp. 556-561, 2015 .

42. M. Guarnieri, "Solidifying Power Electronics [Historical]," IEEE Industrial Electronics Magazine, vol. 12, no. 1, pp. 36-40, 2018.

43. Zhang et al., "A High-Efficiency DC-DC Boost Converter for a Miniaturized Microbial Fuel Cell," IEEE Transactions on Power Electronics, vol. 30, no. 4, pp. 2041-2049, 2015.

44. Singh, A. Kumar, and SpringerLink, Analysis and Design of Power Converter Topologies for Application in Future More Electric Aircraft. 2018.

45. J. Lu, H. Bai, A. Brown, M. McAmmond, D. Chen, and J. Styles, "Design consideration of gate driver circuits and PCB parasitic parameters of paralleled E-mode GaN HEMTs in zero-voltageswitching applications," presented at the 2016 IEEE Applied Power Electronics Conference and Exposition (APEC), Long Beach, CA, USA,

46. C.-H. Lee, C.-Y. Yao, H.-C. Li, D.-B. Lin, and H.-P. Lin, "The study of PCB ground area and location on EMI reduction effectiveness," presented at the 2017 Progress in Electromagnetics Research Symposium - Fall (PIERS - FALL), Singapore, Singapore, 2017.

47. J. Xiaosong and Z. Runjing, "Crosstalk Analysis and Simulation in High-Speed PCB Design," presented at the 2007 8th International Linearization of a Boost Converter With Mixed Load (Constant

Conference on Electronic Measurement and Instruments, Xi'an, China, 2007

48. M. Andersen, "Trends in internet of things platforms," The ACM Magazine for Students, vol. 22, no. 2, pp. 40-43, 2015.

49. B. D. Czejdo and M. Baszun, "Collaborative component engineering and software development," presented at the SoutheastCon 2017, Charlotte, NC, USA, 2017.

50. C. Wang, M. Armstrong, and S. Gadoue, "System identification and adaptive control of a DC-DC converter using a current balancing ON/OFF control technique for optimal transient performance," presented at the 2015 17th European Conference on Power Electronics and Applications (EPE'15 ECCE-Europe), Geneva, Switzerland, 2015.

51. Firoozian and Riazollah, Feedback Control Theory (In Servo Motors and Industrial Control Theory). Boston: MA: Springer US, 2009.

52. L. Guo, "DESIGN AND IMPLEMENTATION OF DIGITAL CONTROLLERS FOR BUCK AND BOOST CONVERTERS USING LINEAR AND NONLINEAR CONTROL METHODS", Degree of Doctor of Philosophy, Auburn University, 2006.

\section{AUTHOR PROFILE}

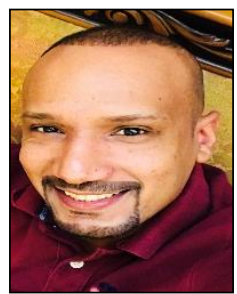

Khaled S AlRasheed, (B.Sc.Eng 1998-MS 2010 PHD 20221), is currently an Senior specialized engineer at Public Authority for Applied Education and Training-Higher Institute of Energy(HIE)-Electrical Power Department (PAAET). He received B. Eng. (V Good) in Electrical and Electronics Engineering from New Mexico State University (USA), and later received MSc from University of Mansour Egypt in Electrical Engineering. He was later Leadership at HIE-Students Affairs (2012-2016), then a Leadership at HIE-Training Committee, and Adviser in the scientific club in Kuwait (Since 2008). PHD in Islamic International University of Malaysia. Interest in Renewable Energy (solar), Power Electronics.

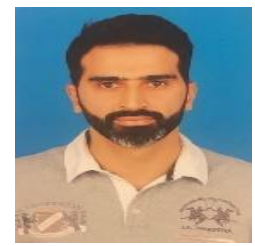

Muhammad R A A Jamal, B. Sc. in Electrical Engineering, M.Sc. in Embedded Systems and Instrumentations. Spent 6 years in the instrumentation and control engineering at Doha Power Station, Kuwait. Currently member of training staff in the Higher Institute of Energy PAAET, Kuwait, since 2008. Dedicated in industrial automation and sensors. Worked as embedded system consultant in prototypes development.

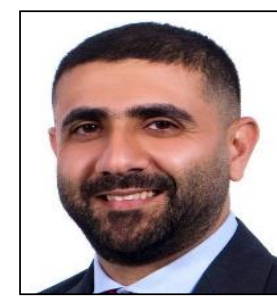

Meshari J AlJandal, (B.Sc.Eng 2005-MS 2019), is currently a specialized engineer at Public Authority for Applied Education and Training-Higher Institute of Energy(HIE)Electrical Power Department (PAAET). He received B. Eng. (V Good) in Electrical Engineering from Kuwait University, and later received MSc from University of Newcastle upon Tyne in Automation and control. He was working as maintenance engineer at wire cable manufacturing (2005-08), then promoted as senior production enginee (2008-2010), then a Leadership at product development firm Worked as consultant in prototypes development (since 2015).

Published By:

Blue Eyes Intelligence Engineering and Sciences Publication (BEIESP)

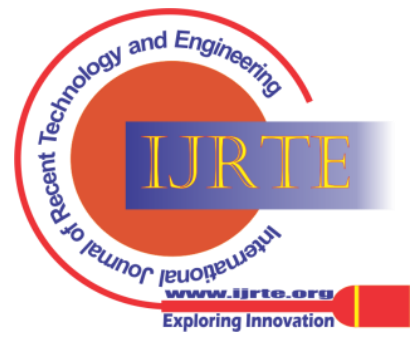

